\title{
Meeting needs-pushing boundaries: Mechanical circulatory support in children; year in review
}

Shriprassad Deshpande, MBBS, MS, ${ }^{a}$ and Bahaaldin Alsoufi, MD $^{\mathrm{b}}$

Application of mechanical circulatory support (MCS) in children has become mainstream. However, it continues to be associated with significant morbidity. The persistent progress in the field of MCS in children has led to increased use, expanded device utilization, and improved survival. In the current review, we focus on publications from the year 2020 that examined the role of MCS in children. We include publications related to total artificial heart (TAH) and ventricular assist devices (VAD), although we do not include those related to acute extracorporeal membrane oxygenation (ECMO) support.

\section{OVERVIEW OF MCS USE IN CHILDREN}

Several registry reports in 2020 shed the light on current MCS practice in children. For example, Morales and colleagues ${ }^{1}$ published the fourth Pediatric Interagency Registry for Mechanical Circulatory Support (Pedimacs) report that outlined outcomes of MCS use at 44 participating centers from 2012 to 2019. In that report, there was a clear and steady increase in MCS utilization. Compared with the third report (2012-2017), which included 508 devices, the number of devices nearly doubled during 2 additional years (2017-2019) to reach 1031 devices in 856 patients. Cardiomyopathy was the most common diagnosis $(58 \%)$, followed by congenital heart disease $(25 \%)$ and myocarditis $(10 \%)$. Implantable continuous (IC) flow devices (eg, HeartWare HVAD [Medtronic, Minneapolis, Minn] and Heartmate 3 [Abbott, Abbott Park, Ill]) were most commonly used, usually in larger children, although it seems that they are being used in smaller children than before (mean age, $13.2 \pm 3.9$ years). These were followed by paracorporeal pulsatile (PP) and continuous (PC) flow devices that were commonly used in younger children who were also more likely to have advanced heart failure stage with $31 \%$ to $46 \%$ of them having Interagency Registry for Mechanically Assisted Circulatory Support profile 1.

From the a'Department of Cardiology and Cardiac Critical Care, Children's National Hospital, Washington, DC; and ${ }^{\mathrm{b}}$ Department of Cardiovascular and Thoracic Surgery, University of Louisville School of Medicine, Norton Children's Hospital, Louisville, Ky.

Received for publication April 1, 2021; revisions received April 1, 2021; accepted for publication April 6, 2021; available ahead of print April 24, 2021.

Address for reprints: Bahaaldin Alsoufi, MD, Department of Cardiovascular and Thoracic Surgery, University of Louisville School of Medicine, Norton Children's Hospital, 201 Abraham Flexner Way, Suite 1200, Louisville, KY 40202 (E-mail: balsoufi@hotmail.com).

J Thorac Cardiovasc Surg 2021;162:400-4

$0022-5223 / \$ 36.00$

Copyright (c) 2021 by The American Association for Thoracic Surgery

https://doi.org/10.1016/j.jtcvs.2021.04.051

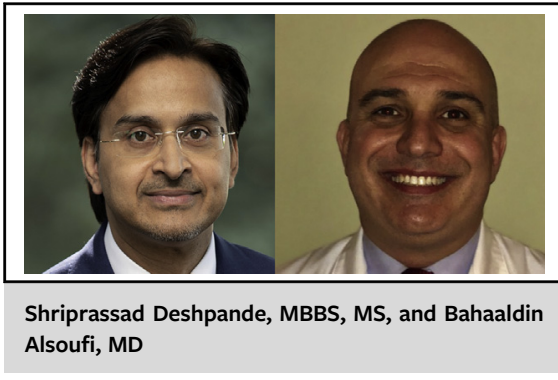

CENTRAL MESSAGE

The persistent progress in the field of mechanical circulatory support in children has led to increased use, expanded device utilization, and improved survival.

These differences likely explain the higher survival of IC compared with PP and PC (92\% vs $81 \%$ vs $68 \%$ at 6 months, respectively). Overall, major adverse events continue to be common with $56 \%$ experiencing at least 1 major event. The incidence of cerebrovascular events seemed to have decreased to $11 \%$, with IC devices having fewer ischemic events compared with PP and PC devices. Finally, whereas destination therapy remains uncommon $(1.3 \%)$, VAD support as bridge to recovery increased $(7.6 \%)$. Of children receiving PC devices, $22.6 \%$ were used as bridge to recovery (potentially, some of these children would have been supported with ECMO in a previous era). ${ }^{1}$

MCS support as bridge to heart transplantation (HT) remains the most common indication in children. This year, Marcos-Alonso and colleagues ${ }^{2}$ published a report from the Spanish Pediatric Heart Transplant Registry Group aiming to examine the influence of MCS on pediatric HT survival. They identified 121 children who underwent HT and compared posttransplant survival between those who had MCS at transplantation versus not. Although they found that posttransplant survival was comparable between the 2 groups, they also found that the type of support had a significant influence on HT outcomes. Posttransplant survival at 1 year with ECMO support was significantly lower at $60 \%(P=.03)$, compared with Excor (Berlin Heart, 
Philadelphia, Pa) $(100 \%)$, other VAD $(85.7 \%)$, or biventricular VAD (BiVAD) $(67 \%))^{2}$

In another analysis of the Pedimacs registry, Baez Hernandez and colleagues ${ }^{3}$ examined the utilization and outcomes of BiVAD support in children. They noted a trend toward lesser utilization of BiVAD in recent years. To assess whether the reported lower survival with BiVAD is related to patient versus device factors, they performed a propensity score match analysis of children who underwent left VAD versus BiVAD support. Overall, $85 \%$ of BiVAD patients were either alive awaiting HT $(32.5 \%)$ or transplanted $(52.5 \%)$ at 6 months after BiVAD implant. BiVAD patients were more likely to experience adverse events in the form of bleeding. They concluded that the usually reported differences in survival between children on BiVAD and left VAD support are likely related to different patient characteristics and severity of illness as opposed to the devices themselves (despite the higher bleeding events). ${ }^{3}$

This is an important issue given that the incidence of right heart failure following left VAD is high and associated with high mortality. Another study from the Pedimacs registry by Simpson and colleagues ${ }^{4}$ noted that $55 \%$ of children who received left VAD had right heart failure between 1 week to 1 month following implantation; and that right heart failure was associated with high morbidity and mortality. They identified factors associated with right heart failure such as younger age, smaller weight, Interagency Registry for Mechanically Assisted Circulatory Support profile 1, chemical paralysis, and pulsatile flow VAD, and suggested that developing a rigorous risk model of right heart failure in children should be considered to potentially lower mortality risk. ${ }^{4}$

\section{NEWER DEVICES AND TECHNIQUES}

Several reports in 2020 highlighted the use of innovative techniques devices in MCS of pediatric patients. Schweiger and colleagues ${ }^{5}$ reported outcomes of BiVAD support in children using HeartWare HVAD. They reported 10 children (median age, $12.7 \pm 4.6$ years; median body surface area, $1.56 \mathrm{~m}^{2}$ ). Overall survival was 6 out of 10,5 were transplanted and 1 awaiting HT, and none recovered. ${ }^{5}$ This report highlights another BiVAD support option in older children; however, the decision to do that versus different right heart support option (eg, medical, ECMO, $\mathrm{PC}$ for right heart support, or BiVAD with PP devices) continues to be challenging.

$\mathrm{O}^{\prime}$ Connor and colleagues ${ }^{6}$ described the initial experience with HeartMate 3 as part of the Advanced Cardiac Therapies Improving Outcomes Network with focus on pediatric patients and adults with congenital heart disease. HeartMate 3 was implanted in 35 patients with median age of 15.7 years (range, 8.8-47.3 years) and median weight of $65.7 \mathrm{~kg}$ (range, $19.1-114.1 \mathrm{~kg}$ ). Congenital heart disease was present in $6(17 \%)$ and 14 patients $(40 \%)$ weighing
$<60 \mathrm{~kg}$. Outcomes were excellent, with only 1 mortality in the cohort. Overall, $20(57 \%)$ underwent HT (median waiting time, 40 days) and there were no strokes or pump thrombosis events reported during the study period. As such, HeartMate 3 provides a reasonable implantable alternative to HeartWare HVAD in pediatric patients. It is important to note that the time to HT in these larger children continues to be short compared with that in adult populations, and that might explain the difference in reported morbidity in this patient population.

TAH is considered in a subset of patients with biventricular failure. Woods and colleagues ${ }^{7}$ presented outcomes of their innovative biventricular support of small children $(<10 \mathrm{~kg})$ in the form of TAH. ${ }^{7}$ They describe creation of TAH with excision of the ventricular mass and use of valved conduits for inflow and outflow connections to paracorporeal centrifugal or pulsatile pumps (Figure 1). They propose this strategy as alternative to BiVAD in small children $(<7 \mathrm{~kg})$ and selected children 7 to $10 \mathrm{~kg}$ in weight and discuss their rational for that approach as opposed to BiVAD. Of note, 3 out of 5 children were done as salvage procedure. Three children underwent successful HT with good clinical status at follow-up. The report is significant for detailed thought process and learned modifications with evolving experience. Accumulation of experience with regard to patient selection, pump factors, and surgical strategy will likely improve outcomes of this type of TAH support.

\section{SINGLE VENTRICLE ANATOMY AND VAD USE}

Among the most significant shifts in MCS in children has been the optimism around our ability to support patients with single ventricle (SV) anatomy. This was reflected in various publications in the year 2020. Philip and colleagues ${ }^{8}$ published their experience using VAD support for patients with SV anatomy either as primary support or after palliative procedures. Using Excor, they were successful in supporting 2 out of 3 of those who had prior palliative procedures (Norwood, pulmonary artery band, and hybrid first stage, 1 each) and 4 out of 6 of those in whom VAD was their initial operation (4 with hypoplastic left heart syndrome underwent concomitant hybrid first stage, 2 with pulmonary atresia or intact ventricular septum underwent patent ductus arteriosis stent or Y shunt to pulmonary artery from outflow cannula). ${ }^{8}$ This is a unique experience in neonates with extremely challenging conditions and the initial results are encouraging considering the otherwise expected poor prognosis (Figure 2). Only few other surgeons and centers have applied a similar strategy, including the author of this article (B.A.). There is a lot to learn from this experience that is nicely described by Philip and colleagues ${ }^{8}$ from the University of Florida.

Chen and colleagues ${ }^{9}$ from Stanford University reported outcomes of 14 children with SV who received VAD support. Although they noted that supporting SV patients 


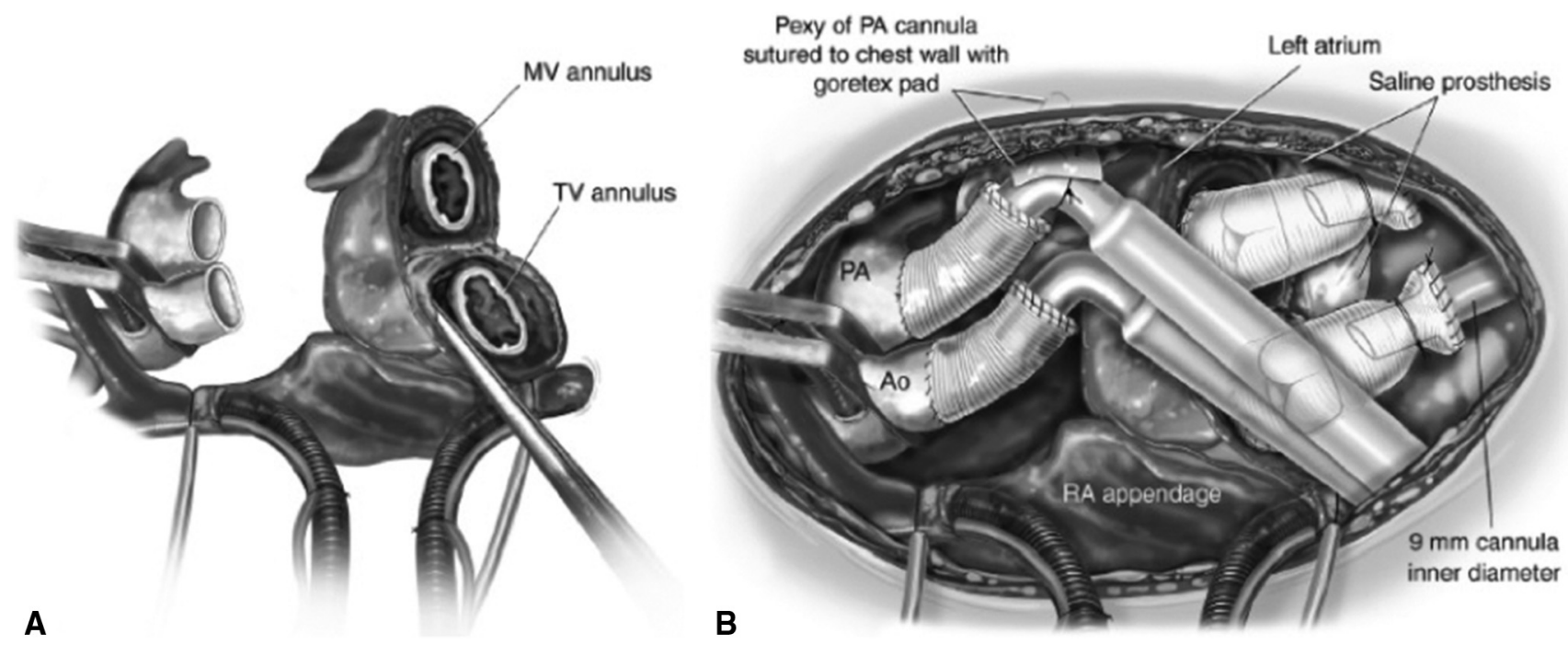

FIGURE 1. Method of total artificial heart implantation in a young patient with a biventricular circulation. Appearance after resecting the ventricular mass, leaving the inflow annuli (A), and completing the inflow and outflow connections (B). Porcine valved polyethylene terephthalate conduits were used for the left and right inflows. Inflow and outflow cannulas were Excor cannulas (Berlin Heart Inc, The Woodlands, Tex). Note the saline implant placed leftward and inferior, to maintain sufficient pericardial space for subsequent transplantation. Either pulsatile or centrifugal pumps can he used with this arrangement. $M V$, Mitral valve; $T V$, tricuspid valve; $P A$, pulmonary artery; $A o$, aorta; $R A$, right atrium. Reproduced with permission. ${ }^{4}$

with failing Fontan was generally successful in their experience, they reported significant mortality $(80 \%)$ in those supported with the Glenn physiology. ${ }^{9}$ They suggested either conversion to shunt physiology or moving on to Fontan operation plus simultaneous VAD as alternative ways to be able to support these patients given the numerous physiologic challenges in children with Glenn physiology that they described nicely in their discussion section. ${ }^{9}$ It is likely that patient selection and institutional experience affect MCS outcomes in children with SV anatomy, and that might explain different results and conclusions from various institutions. Granegger and colleagues ${ }^{10}$ reported outcomes of MCS in 33 children and found that MCS in children with SV anatomy was associated with inferior 1-year survival compared with patients with biventricular circulation $(50 \%$ vs $80 \%)$.
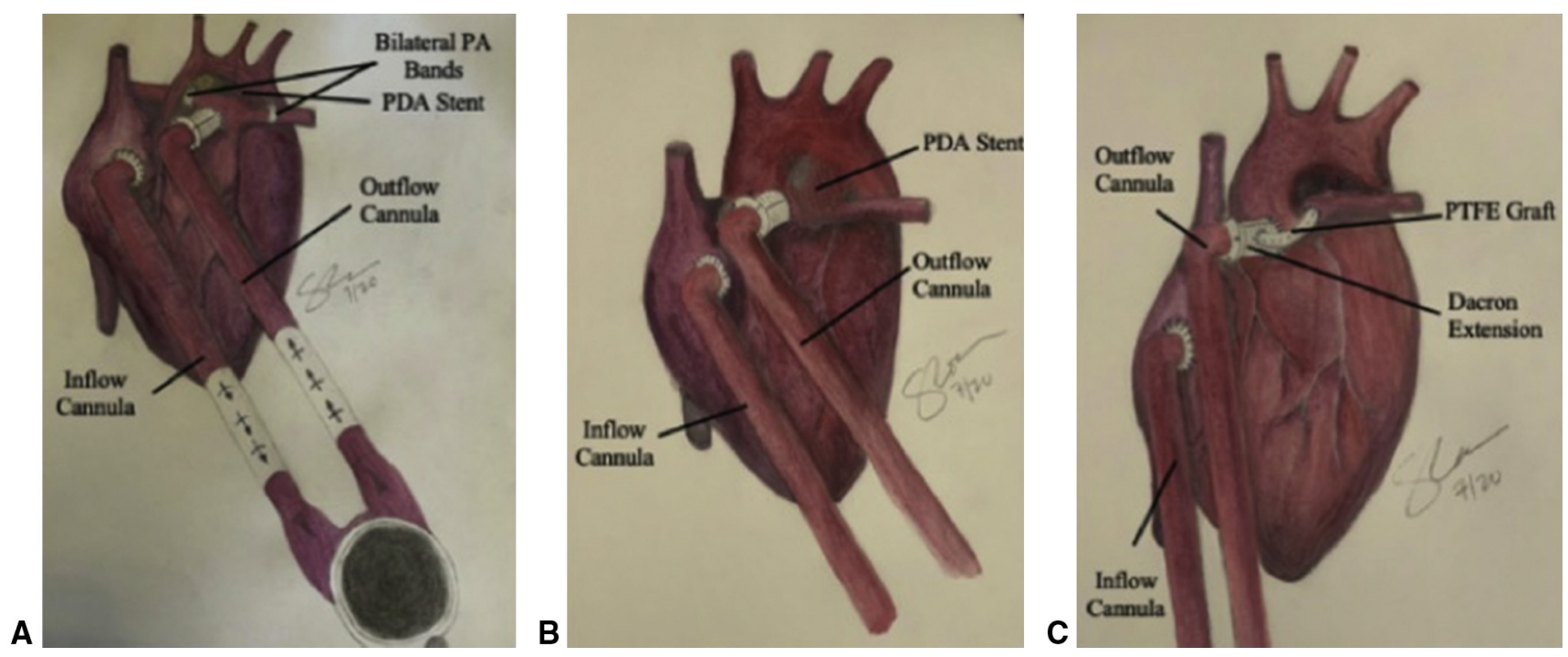

FIGURE 2. Depictions of ventricular assist device support in the single ventricle. A, Ventricular assist device with hybrid palliation. Patent ductus arteriosus $(P D A)$ stent and bilateral pulmonary artery $(P A)$ hands. Inflow cannula to the right atrium and outflow cannula to the PA. B, Ventricular assist device with PDA stent. Inflow cannula to the right atrium and outflow cannula to the ascending aorta. $C$, Ventricular assist device with a polytetrafluoroethylene graft connecting the outflow cannula to the pulmonary artery. Inflow cannula to the right atrium and outflow cannula to the ascending aorta. PTFE, Polytetrafluoroethylene. 
Finally, an excellent review about MCS in the failing Fontan was published by Villa and colleagues. ${ }^{11}$ In that review, they discuss the available literature about this topic and point out the importance of understanding of the pathophysiology of Fontan failure and of proper timing and pattern of support. There is a lot to learn from this excellent review from Cincinnati. ${ }^{11}$

\section{HEMATOLOGIC ISSUES IN MCS SUPPORT}

With an increase in the use of implantable continuous flow devices in children, the rheologic performance of these pumps in children needs to be carefully studied. Granegger and colleagues ${ }^{12}$ produced an elegant report that included clinical data along with in silico and in vitro analysis of blood trauma in pediatric patients supported with HeartWare HVAD. The clinical cohort included 14 patients (body surface area, $1.19 \pm 0.36 \mathrm{~m}^{2}$ ) with 60-day survival of $90 \%$ but $43 \%$ of these patients experiencing a major bleeding event in the first 8 weeks of implantation. Further modeling showed that lower pump speeds and lower flows in pediatric patients compared with adult counterparts result in significant blood trauma. ${ }^{12}$ Studies such as these will be important to improve our understanding of pump performance in pediatric patients. Pediatric-specific devices as well as implantation and management strategies will be needed to mitigate the morbidity.

On a related note, the use of direct thrombin inhibitors (bivalirudin or argatroban) as an alternative anticoagulant (to heparin) is gaining support in the community. Various reports have outlined the use and safety of bivalirudin in pediatric VAD patients and may suggest superiority to unfractionated heparin. $^{13,14}$

\section{CONCLUSIONS}

The year saw validation of continued use of MCS in pediatric patients, mainly as bridge to transplantation with increased use as bridge to recovery. The outcomes in cardiomyopathy and some congenital heart disease patients continue to be good. However, supporting children with SV anatomy continues to be a challenge for the field. Innovative surgical approaches to supporting these patients combined with better use of technology will be necessary to optimize their care.

\section{Conflict of Interest Statement}

The authors reported no conflicts of interest.

The Journal policy requires editors and reviewers to disclose conflicts of interest and to decline handling or reviewing manuscripts for which they may have a conflict of interest. The editors and reviewers of this article have no conflicts of interest.

\section{References}

1. Morales DLS, Adachi I, Peng DM, Sinha P, Lorts A, Fields K, et al. Fourth annual pediatric interagency registry for mechanical circulatory support (Pedimacs) report. Ann Thorac Surg. 2020;110:1819-31.

2. Marcos-Alonso S, Gil N, García-Guereta L, Albert D, Tejero MÁ, Perez-Villa F, et al. Impact of mechanical circulatory support on survival in pediatric heart transplantation. Pediatr Transplant. 2020;24:e13707.

3. Baez Hernandez N, Kirk R, Sutcliffe D, Davies R, Jaquiss R, Gao A, et al. Utilization and outcomes in biventricular assist device support in pediatrics. $J$ Thorac Cardiovasc Surg. 2020;160:1301-8.e2.

4. Simpson KE, Kirklin JK, Cantor RS, Mehegan M, Lamour JM, Guleserian KJ, et al Right heart failure with left ventricular assist device implantation in children: an analysis of the Pedimacs registry database. J Heart Lung Transplant. 2020;39:231-40.

5. Schweiger M, E Mascio C, Kanter KR, Marasco S, Eghtesady P, Miera O, et al. Intracorporeal biventricular assist devices using the HeartWare ventricular assist device in children. ASAIO J. 2020;66:1031-4.

6. O’Connor MJ, Lorts A, Davies RR, Fynn-Thompson F, Joong A, Maeda K, et al. Early experience with the HeartMate 3 continuous-flow ventricular assist device in pediatric patients and patients with congenital heart disease: a multicenter registry analysis. J Heart Lung Transplant. 2020;39:573-9.

7. Woods RK, Kindel S, Mitchell ME, Hraska V, Niebler RA. Evolving understanding of total artificial heart support of young infants and children. J Thorac Cardiovasc Surg. 2020;159:1075-82.

8. Philip J, Powers E, Machado D, Colon DL, Gupta D, Shih R, et al. Pulsatile ventricular assist device as a bridge to transplant for the early high-risk single-ventricle physiology. J Thorac Cardiovasc Surg. 2021;162:405-13.

9. Chen S, Rosenthal DN, Murray J, Dykes JC, Almond CS, Yarlagadda VV, et al. Bridge to transplant with ventricular assist device support in pediatric patients with single ventricle heart disease. ASAIO J. 2020;66:205-11.

10. Granegger M, Schlöglhofer T, Riebandt J, Schlager G, SkhirtladzeDworschak K, Kitzmüller E, et al. Mechanical circulatory support in pediatric patients with bi- and univentricular hearts. J Thorac Cardiovasc Surg Open 2020 [Epub ahead of print].

11. Villa CR, Alsaied T, Morales DLS. Ventricular assist device therapy and Fontan: a story of supply and demand. Semin Thorac Cardiovasc Surg Pediatr Card Surg Annu. 2020;23:62-8.

12. Granegger M, Thamsen B, Schlöglhofer T, Lach S, Escher A, Haas T, et al. Blood trauma potential of the HeartWare ventricular assist device in pediatric patients. $J$ Thorac Cardiovasc Surg. 2020;159:1519-27.

13. VanderPluym CJ, Cantor RS, Machado D, Boyle G, May L, Griffiths E, et al. Utilization and outcomes of children treated with direct thrombin inhibitors on paracorporeal ventricular assist device support. ASAIO J. 2020;66:939-45.

14. Bates A, Buchholz H, Freed D, MacArthur R, PiDBorochynski T, Conway J. Bi valirudin experience in a heterogeneous ventricular assist device population. ASAIO J. 2020;66:677-82.

Key Words: mechanical circulatory support, pediatric heart transplantation, ventircular assist device 


\section{Mechanical circulatory support in children: Recent articles in AATS journals}

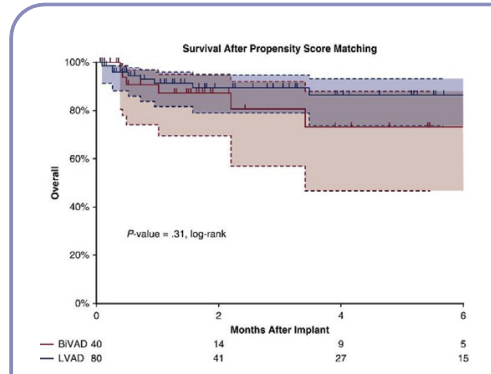

JTCVS: Utilization and outcomes in biventricular assist device support in pediatrics. Baez Hernandez N, Kirk R, Sutcliffe D, Davies R, Jaquiss R, Gao A, Zhang S, Butts RJ. J Thorac Cardiovasc Surg. 2020;160(5):1301-1308.

Commentary: Is two ever better than one in pediatric ventricular assist device support? The controversy continues. Riggs KW, Morales DLS, Zafar F. J Thorac Cardiovasc Surg. 2020;160(5): 1309-1310.

Commentary: To BiVAD or not to BiVAD...That is the question? Dykes JC, Maeda K. J Thorac Cardiovasc Surg. 2020;160(5):1310-1311.

Commentary: Two sides of the same coin: Competing biventricular assist device outcomes from Pediatric Interagency Registry for Mechanical Circulatory Support data. Moon J, Adachi I. J Thorac Cardiovasc Surg. 2020;160(5):1311-1312.

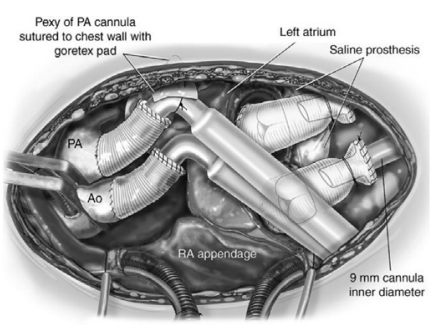

JTCVS: Evolving understanding of total artificial heart support of young infants and children. Woods RK, Kindel S, Mitchell ME, Hraska V, Niebler RA. J Thorac Cardiovasc Surg. 2020;159(3):1075-1082.

Commentary: To remove (a heart), or not to remove, that is the question. Hope K, Adachi I. J Thorac Cardiovasc Surg. 2020;159(3):1083-1084.

Commentary: Disappointments are often the positive stepping stones towards success: Expanding the use of total artificial hearts to infants. Thangappan K, Morales DLS. J Thorac Cardiovasc Surg. 2020;159(3):1085.

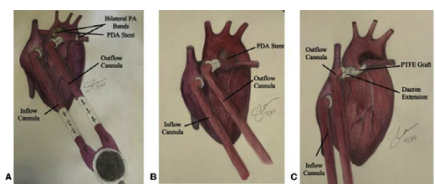

JTCVS: Pulsatile ventricular assist device as a bridge to transplant for the early high-risk single-ventricle physiology. Philip J, Powers E, Machado D, Colon DL, Gupta D, Shih R, Ebraheem M, Fudge C, Bleiweis M. J Thorac Cardiovasc Surg. 2021 [In Press].

Commentary: Ventricular assist device support in an early infancy with single ventricle: Transformation from salvage to elective. Moon J, Adachi I. J Thorac Cardiovasc Surg. 2021 [In Press].

Commentary: How to VAD to avoid BAD in high-risk single ventricle. Lee MM, Honjo O. J Thorac Cardiovasc Surg. 2021 [In Press].

Commentary: Promise with pulsatility? Early bridging of high-risk patients with singleventricle physiology with a ventricular assist device. Simón Morales DL, Perry T. J Thorac Cardiovasc Surg. 2021 [In Press].

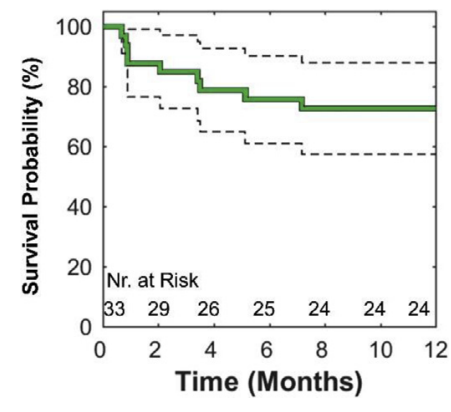

JTCVS Open: Mechanical circulatory support in pediatric patients with bi- and univentricular hearts. Granegger M, Schlöglhofer T, Riebandt J, Schlager G, SkhirtladzeDworschak K, Kitzmüller E, Michel-Behnke I, Laufer G, Zimpfer D. J Thorac Cardiovasc Surg Open. 2021 [In Press].

Commentary: Towards mechanical circulatory support in univentricular hearts. Huebler $M$, Biermann D, Sachweh JS. J Thorac Cardiovasc Surg Open. 2021 [In Press]. 